\title{
Controle genético do teor proteico nos grãos e de caracteres agronômicos em milho cultivado com diferentes níveis de adubação nitrogenada
}

\author{
Luíce Gomes Bueno(1), Lázaro José Chaves(1), Jaison Pereira de Oliveira(2), Edward Madureira Brasil(1), \\ Américo José dos Santos Reis ${ }^{(1)}$, Aracelle Assunção(1), André Ferreira Pereira ${ }^{(3)}$ e Michele Ribeiro Ramos ${ }^{(1)}$
}

\begin{abstract}
(1)Universidade Federal de Goiás, Escola de Agronomia e Engenharia de Alimentos, Campus Samambaia, Caixa Postal 131, CEP 74001-970 Goiânia, GO. E-mail: lugobueno@bol.com.br, Ichaves@agro.ufg.br, ebrasil@reitoria.ufg.br, americo@agro.ufg.br, aracelleassuncao@gmail.com, micheleribeiroramos@hotmail.com (2)Embrapa Arroz e Feijão, Caixa Postal 179, CEP 75375-000 Santo Antônio de Goiás, GO. E-mail: jaison@cnpaf.embrapa.com ${ }^{(3)}$ |nstituto Federal de Educação, Ciência e Tecnologia de Brasília, Campus Planaltina, Caixa Postal 08202, CEP 73301-970 Planaltina, DF. E-mail: anrpereira@gmail.com
\end{abstract}

\begin{abstract}
Resumo - O objetivo deste trabalho foi determinar o controle genético do teor de proteína em grãos e de caracteres agronômicos de milho (Zea mays) cultivado com diferentes níveis de adubação nitrogenada. Foram avaliados nove genitores de milho e seus híbridos, em dialelo completo, com dois níveis de adubação nitrogenada. Os caracteres avaliados foram: índice relativo de clorofila, altura de plantas, altura de espigas, produção de espigas, produção de grãos, coloração de grãos, massa de cem grãos, densidade de grãos, teor de nitrogênio nas folhas e teor de proteína nos grãos. A elevação da adubação nitrogenada promoveu aumento nos caracteres índice relativo de clorofila, altura de espigas e teor de proteínas nos grãos. Apenas a variável produção de grãos apresentou controle genético distinto nos diferentes níveis de nitrogênio. A análise dialélica mostrou significância dos efeitos dos genótipos sobre todos os caracteres, com exceção da produção de espigas e de grãos, e foi possível observar significância da heterose na maioria das variáveis. Para o teor de proteínas nos grãos, não houve significância da capacidade específica de combinação, e a capacidade geral de combinação dos genótipos teve efeito mais importante na manifestação desse caráter.
\end{abstract}

Termos para indexação: Zea mays, análise de dialelo, capacidade de combinação, qualidade da proteína.

\section{Genetic control of grain protein content and of agronomic traits in maize cultivated at different levels of nitrogen fertilization}

\begin{abstract}
The objective of this work was to determine the genetic control of grain protein content and of the agronomic traits of corn (Zea mays) at different levels of nitrogen fertilization. Nine parent populations and their hybrids were evaluated in a complete diallel mating design, with two levels of nitrogen fertilization. The variables evaluated were: relative chlorophyll index, plant height, ear height, ear production, grain yield, grain color, mass of 100 grains, density of grains, nitrogen content in the leaves and grain protein content. Increasing levels of nitrogen fertilization increased the relative chlorophyll index, ear height and grain protein content. However, only grain production had distinct genetic control at different levels of nitrogen. Diallel analysis showed significant genotype effect in all traits, except for grain and ear production. For most of the variables, there was significance of heterosis effect. For grain protein content, there was no significance for specific combining ability, and genotypes general combining ability had more important effects in the expression of this character.
\end{abstract}

Index terms: Zea mays, diallel analysis, combining ability, protein quality.

\section{Introdução}

O milho é tido como uma das principais culturas do mundo, e sua importância está associada à versatilidade em sua utilização, pois é considerado um alimento energético para dietas humanas e animais, com potencial para ser aproveitado também como fonte proteica (Paes, 2006). No entanto, o melhoramento genético voltado principalmente para o aumento de produtividade e de outras características agronômicas desejáveis fez com que o milho perdesse valor nutricional, especialmente com diminuição nos teores de proteína e óleo. Segundo Lima \& Bellaver (1999), este fato está relacionado à correlação negativa existente entre produtividade e percentagem de proteína e óleo.

Há uma série de fatores que pode afetar o valor nutritivo do milho, desde características genéticas da cultivar até o manejo do sistema de produção. A disponibilidade de nitrogênio $(\mathrm{N})$ é considerada relevante, pois esse elemento é constituinte de enzimas, 
vitaminas, aminoácidos e proteínas presentes no grão (Lea \& Azevedo, 2006).

$\mathrm{Na}$ tentativa de transformar o milho num alimento mais completo nutricionalmente, uma abordagem com exploração dos controles genéticos conhecidos de teores de nutrientes nos grãos de milho, associada ao aumento no aproveitamento de $\mathrm{N}$ pela planta e na sua conversão em proteína, sem prejuízo acentuado no rendimento de grãos, representa grande desafio a ser alcançado pelo melhoramento genético. Diferentes pesquisas têm mostrado variações inter e intraespecíficas no acúmulo e utilização de $\mathrm{N}$ entre cereais (Medici et al., 2004, 2005), e a tendência dessas plantas de somente aumentar o conteúdo de proteína nos grãos quando suas produtividades se aproximam da produtividade máxima.

O método de cruzamentos dialélicos tem sido relatado em vários estudos para a melhoria da qualidade nutricional em milho (Rodrigues \& Chaves, 2002; Oliveira et al., 2004; Rodrigues et al., 2006; Jesus et al., 2008). Esse método tem ocupado lugar de destaque no melhoramento e é de grande valia, quando se deseja conhecer o comportamento de genitores e o potencial de cada um na formação de combinações híbridas. Por meio da análise dialélica, é possível determinar os efeitos aditivos e não aditivos no controle genético de uma característica de interesse (Souza et al., 2008).

O objetivo deste trabalho foi determinar o controle genético do teor de proteínas nos grãos e de caracteres agronômicos de milho, cultivado com diferentes níveis de adubação nitrogenada.

\section{Material e Métodos}

Omaterial experimental foi constituído depopulações derivadasdehíbridoscomerciais(Tabela 1), inicialmente intercruzados num esquema dialélico completo. A partir

Tabela 1. Híbridos comerciais simples (HS) e triplos (HT), utilizados como parentais no dialelo.

\begin{tabular}{cccc}
\hline População & Material & Empresa ou marca comercial & Tipo de híbrido \\
\hline 1 & DKB 333B & Monsanto & HS \\
2 & AG 7575 & Agroceres & HS \\
3 & DAS 2C 599 & Dow AgroSciences & HS \\
4 & DAS CO32 & Dow AgroSciences & HT \\
5 & DAS 8420 & Dow AgroSciences & HS \\
6 & GARRA & Syngenta Seeds & HT \\
7 & AGN 31A31 & Agromen & HS \\
8 & P 30F33 & Pioneer & HS \\
9 & AS 1548 & Agroest & HS \\
\hline
\end{tabular}

destes, foram avaliados 49 genótipos, constituídos por nove populações parentais, 36 híbridos provenientes de cruzamentos dialélicos e quatro testemunhas: QPM 1, UFG-Samambaia, Emgopa-Óleo e P-30 K75.

A instalação do experimento foi realizada na época de safrinha, na área experimental da Escola de Agronomia e Engenharia de Alimentos, da Universidade Federal de Goiás, Goiânia, GO (16²35'12"S, 49²1'14"W, altitude $730 \mathrm{~m}$ ), em abril de 2005, com irrigação. O solo é do tipo Latossolo Vermelho (Santos et al., 2006), que apresentou, pela análise química nos primeiros $20 \mathrm{~cm}$ de profundidade: $\mathrm{pH}$ 5,3; matéria orgânica, $21 \mathrm{~g} \mathrm{~kg}^{-1} ; \mathrm{P}, 2,3 \mathrm{mg} \mathrm{dm}{ }^{-3} ; \mathrm{K}, 0,26 \mathrm{cmol}_{\mathrm{c}} \mathrm{dm}^{-3} ; \mathrm{Ca}$, $3,1 \mathrm{cmol}_{\mathrm{c}} \mathrm{dm}^{-3} ; \mathrm{Mg}, 1,1 \mathrm{cmol}_{\mathrm{c}} \mathrm{dm}^{-3} ; \mathrm{Al}, 0 \mathrm{cmol}_{\mathrm{c}} \mathrm{dm}^{-3}$; $\mathrm{H}+\mathrm{Al}, 2,8 \mathrm{cmol}_{\mathrm{c}} \mathrm{dm}^{-3}$; e CTC, 7,3 $\mathrm{cmol}_{\mathrm{c}} \mathrm{dm}^{-3}$. A área do experimento foi a mesma utilizada na obtenção das populações avaliadas.

$\mathrm{Na}$ avaliação do dialelo, foi utilizado o delineamento experimental em látice quadrado $7 \times 7$, em parcelas subdivididas, com três repetições. Cada parcela experimental foi dividida em duas subparcelas de cinco linhas, com $4 \mathrm{~m}$ cada, espaçadas em $0,75 \mathrm{~m}$, com 16 plantas por linha (53.300 plantas por hectare), após o desbaste, no total de 294 parcelas. A adubação de semeadura foi de $400 \mathrm{~kg} \mathrm{ha}^{-1}$ da formulação 5-25-15. Em cobertura, dois níveis de adubação nitrogenada foram usados em cada subparcela: 70 e $140 \mathrm{~kg} \mathrm{ha}^{-1}$ de N, parcelados em duas aplicações - a primeira, com metade da dose de N, realizada aos 26 dias após semeadura, com a formulação 20-0-20, e a segunda, com a outra metade da dose de N, aos 45 dias após semeadura, com ureia. As outras práticas culturais foram realizadas conforme recomendações técnicas para a cultura do milho (Galvão \& Miranda, 2004).

Os caracteres avaliados foram: índice relativo de clorofila "Soil and Plant Analysis Development" (SPAD), medido com uso de clorofilômetro Minolta SPAD-502, aos 90, 97 e 104 dias após a semeadura (C1, C2 e C3, respectivamente), tendo-se avaliado sete plantas em cada subparcela, nas folhas acima da primeira espiga, em posição situada na parte central e a $2 \mathrm{~cm}$ da borda das folhas; altura de plantas (AP) média de altura de plantas, medida do nível do solo ao nó de inserção da folha bandeira; altura de inserção de espigas (AE) - média de altura medida do nível do solo ao nó de inserção da primeira espiga; produção de espigas (PE) - massa total $\left(\mathrm{kg} \mathrm{ha}^{-1}\right)$ de espigas despalhadas, corrigida para $13 \%$ de umidade e para 
o estande utilizado; produção de grãos (PG) - massa de grãos $\left(\mathrm{kg} \mathrm{ha}^{-1}\right)$ corrigida para $13 \%$ de umidade e para o estande; coloração de grãos (Cor) - determinada pela comparação da coloração dos grãos com escala de cores de um gradiente de coloração, que se inicia no amarelo-claro, de valor 1, e finaliza no alaranjado intenso, com valor 15 (Roche, 1987), adaptada por Oliveira (2007); massa de 100 grãos (McemG) - massa de uma amostra de 100 grãos livres de danos de qualquer natureza e com umidade uniforme; densidade real de grãos (Dens) - relação entre a massa de 100 grãos e o volume delimitado por sua superfície externa, obtida a partir do volume de álcool etílico deslocado num recipiente graduado $\left(\mathrm{g} \mathrm{mL}^{-1}\right)$; teor de $\mathrm{N}$ nas folhas (NF) - determinado na primeira folha acima da primeira espiga, aos 73 dias após a semeadura, pelo método de Kjeldahl, por meio da digestão completa com ácido sulfúrico $\left(\mathrm{H}_{2} \mathrm{SO}_{4}\right)$ (Deutsch, 1995); teor de proteína nos grãos (ProtG), determinado com o uso de $100 \mathrm{~g}$ de grãos, a partir do teor de $\mathrm{N}$ total nos grãos (método de Kjeldahl) e da conversão do $\mathrm{N}$ total em proteína bruta pela multiplicação do fator 6,25 (Villegas et al., 1985).

Foi realizada a análise de variância preliminar dos caracteres avaliados dos 49 tratamentos. Em seguida, o efeito de tratamentos foi determinado, segundo Gardner \&Eberhart(1966),pela análise dialélica das populações parentais e híbridos. O modelo é representado por: $\mathrm{Y}_{\mathrm{i} i^{\prime}}=\mu+1 / 2\left(\mathrm{~V}_{\mathrm{i}}+\mathrm{V}_{\mathrm{i}^{\prime}}\right)+\theta\left(\overline{\mathrm{h}}+\mathrm{h}_{\mathrm{i}}+\mathrm{h}_{\mathrm{i}^{\prime}}+\mathrm{S}_{\mathrm{ii}}\right)+\bar{\varepsilon}_{\mathrm{ii}}$, em que: $Y_{\mathrm{ii}}$ é ovalor observadopara ogenitoriou cruzamento entre i e i'; $\mu$ é a média geral dos genótipos; $v_{i}$ é o efeito do i-ésimo genótipo; $v_{i}$ ' é o efeito do i'-ésimo genótipo; $\overline{\mathrm{h}}$ é o efeito da heterose média de todos os cruzamentos; $\mathrm{h}_{\mathrm{i}}$ e $\mathrm{h}_{\mathrm{i}}$ 'é o efeito das heteroses dos genitores i e i', em relação a $\bar{h}$, respectivamente; $s_{\text {ii }}$ é o efeito da heterose específica, resultante do cruzamento entre genitores de ordem i e i'; $\bar{\varepsilon}_{\mathrm{ii}}$ é o erro experimental médio associado às médias dos híbridos ou parentais; $\theta$ é o coeficiente condicional, que assumiu valores de $\theta=0$, para $\mathrm{i}=\mathrm{i}$ e $\theta=1$ para $\mathrm{i} \neq \mathrm{i}$ '. A partir dos efeitos de genótipo $\left(\mathrm{v}_{\mathrm{i}}\right)$ e de heterose de genótipo $\left(\mathrm{h}_{\mathrm{i}}\right)$, foram estimadas as capacidades específica (CEC) e geral de combinação (CGC) de cada genitor $\left(\mathrm{g}_{\mathrm{i}}\right)$, por meio da expressão: $\mathrm{g}_{\mathrm{i}}=1 / 2 \mathrm{v}_{\mathrm{i}}+\mathrm{h}_{\mathrm{i}}$. As análises estatísticas foram realizadas por meio dos procedimentos PROC GLM e IML do SAS (SAS Institute, 2002).

Foi empregada a metodologia apresentada por Miranda Filho \& Vencovsky (1995), para realização da análise dialélica, com o desdobramento dos efeitos principais e interações, quando pertinente.

\section{Resultados e Discussão}

Os genótipos testados tiveram diferenças significativas em todas as variáveis avaliadas (Tabela 2). Apenas as variáveis $\mathrm{C} 2, \mathrm{C} 3, \mathrm{AE}$ e Prot $\mathrm{G}$ foram afetadas pelas doses de $\mathrm{N}$ aplicadas em cobertura. A ausência de resposta ao fornecimento de $\mathrm{N}$, na maioria das variáveis, pode estar relacionada às doses aplicadas do adubo, em que o menor nível não chegou a representar situação de estresse para as plantas.

Os valores médios, máximos e mínimos de todos os caracteres avaliados estão apresentados na Tabela 3. Pode-se observar que, nas três épocas de avaliação do índice relativo de clorofila nas folhas, houve acréscimo nas médias dos tratamentos, com a elevação

Tabela 2. Resumo da análise de variância dos caracteres: índice relativo de clorofila (SPAD), determinado aos 90,97 e 104 dias após semeadura (C1, C2 e C3, respectivamente); altura de planta (AP); altura de espigas (AE); produção de espigas (PE); produção de grãos (PG), coloração de grãos (Cor) $)^{(1)}$; massa de 100 grãos (McemG); densidade real de grãos (Dens); teor de nitrogênio nas folhas (NF); e teor de proteína nos grãos (ProtG).

\begin{tabular}{|c|c|c|c|c|c|c|c|c|c|c|c|c|c|}
\hline \multirow[t]{2}{*}{ Fonte de variação } & \multirow[t]{2}{*}{$\mathrm{GL}^{(2)}$} & \multicolumn{12}{|c|}{ Quadrado médio } \\
\hline & & $\mathrm{C} 1$ & $\mathrm{C} 2$ & $\mathrm{C} 3$ & $\mathrm{AP}$ & $\mathrm{AE}$ & $\mathrm{PE}$ & PG & Cor & McemG & Dens & NF & ProtG \\
\hline Genótipo & 48 & $21,01^{* *}$ & $24,81^{*}$ & $23,48^{* *}$ & $783,25^{* *}$ & $482,57 * *$ & $3.495 .686,77^{* *}$ & $2.258 .623,66^{* *}$ & $2,9532 * *$ & $21,5510^{* *}$ & $0,00079 * *$ & 0,1284* & $1,1079 * *$ \\
\hline Bloco & 20 & $10,75^{\mathrm{ns}}$ & $17,85^{\text {ns }}$ & $15,24 *$ & $123,56^{\text {ns }}$ & $91,90^{\text {ns }}$ & $1.760 .331,02 *$ & $1.100 .078,87^{*}$ & $1,5173 * *$ & $28,9570 * *$ & $0,00180 * *$ & $0,5591 * *$ & $1,4304 * *$ \\
\hline Erro a & 78 & 7,53 & 14,92 & 8,38 & 100,16 & 64,43 & $911.766,71$ & $619.538,25$ & 0,4608 & 4,9572 & 0,00042 & 0,0824 & 0,5832 \\
\hline Nitrogênio & 1 & $17,93^{\mathrm{ns}}$ & $126,30^{*}$ & $96,11 * *$ & $35,67^{\text {ns }}$ & $147,16^{*}$ & $1.302 .330,56^{\mathrm{ns}}$ & $249.296,74^{\text {ns }}$ & $0,0842^{\text {ns }}$ & $9,7987^{\text {ns }}$ & $1,7 \mathrm{E}-05^{\mathrm{ns}}$ & $0,2230^{\text {ns }}$ & $3,7298^{*}$ \\
\hline Genótipo*N & 48 & $6,56^{\mathrm{ns}}$ & $13,07^{\mathrm{ns}}$ & $7,39^{\text {ns }}$ & $47,32^{\text {ns }}$ & $40,97^{\mathrm{ns}}$ & $641.425,10^{\mathrm{ns}}$ & $336.789,54^{*}$ & $0,2934^{\text {ns }}$ & $3,5736^{\mathrm{ns}}$ & $0,00044^{\mathrm{ns}}$ & $0,0679^{\text {ns }}$ & $0,6465^{\mathrm{ns}}$ \\
\hline Erro b & 98 & 6,24 & 18,76 & 9,27 & 46,68 & 33,51 & $461.638,42$ & $206.245,35$ & 0,2509 & 3,8766 & 0,00048 & 0,0659 & 0,5959 \\
\hline Total & 293 & - & - & - & - & - & - & - & - & - & - & - & - \\
\hline Média & & 57,61 & 56,77 & 54,77 & 190,41 & 93,98 & $7.280,78$ & $5.914,30$ & 13,04 & 33,64 & 1,26 & 2,71 & 9,89 \\
\hline CV (\%) & & 4,34 & 7,63 & 5,56 & 3,59 & 6,16 & 9,33 & 7,68 & 3,84 & 5,85 & 1,74 & 9,47 & 7,81 \\
\hline
\end{tabular}

${ }^{(1)}$ Escala de cores composta por gradiente de coloração que se inicia no amarelo-claro, de valor 1, e finaliza no alaranjado intenso, com valor 15 (Roche, 1987). (2)Para as variáveis PE e PG, o número de graus de liberdade (GL) do erro b e total foram 96 e 291, respectivamente; para as variáveis Cor, McemG, Dens e NF, foram 97 e 292, respectivamente; e para a variável ProtG, foram de 77, 96 e 290, respectivamente para o erro a, b e total. * e **Significativos

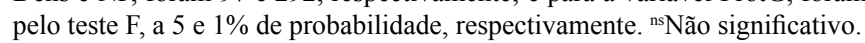


da quantidade aplicada de N. Diferenças significativas foram observadas somente em C2 e C3. A suficiência do $\mathrm{N}$ disponível nos dois níveis de adubação e a menor taxa de remobilização desse nutriente, durante a avaliação em $\mathrm{C} 1$, em comparação a $\mathrm{C} 2$ e $\mathrm{C} 3$, determinaram a não significância do fornecimento de $\mathrm{N}$ sobre essa variável.

Houve variação significativa das médias da altura de espigas e do teor de proteína nos grãos, com o aumento na dose de $\mathrm{N}$ (Tabela 3). Na maior dose, os valores encontrados para ProtG ficaram entre 8,76 e

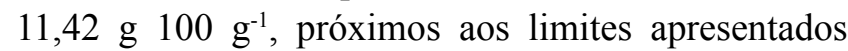

por Ferreira et al. (2001), que encontraram variação

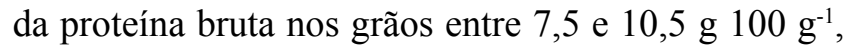
também atribuída à adubação nitrogenada. Esses autores demonstraram a existência de correlação linear positiva da composição química da folha com a composição dos grãos, o que está de acordo com o aumento na ProtG e nas leituras SPAD, observado no presente trabalho, pela elevação nas doses de N.

Apesar de ter sido observada grande variação entre os valores mínimos e máximos de produtividade de grãos (2.836 e $7.419 \mathrm{~kg} \mathrm{ha}^{-1}$ ), não foi observada diferença significativa entre as médias das duas doses

Tabela 3. Valores médios ${ }^{(1)}$, máximos e mínimos, observados nos níveis de adubação nitrogenada de cobertura: $\left(\mathrm{A}, 70 \mathrm{~kg}\right.$ ha ${ }^{-1}$ de $\mathrm{N}$; $\mathrm{B}, 140 \mathrm{~kg} \mathrm{ha}^{-1} \mathrm{de} \mathrm{N}$ ), para os caracteres: índice relativo de clorofila (SPAD), determinado aos 90, 97 e 104 dias após a semeadura (C1, $\mathrm{C} 2$ e C3, respectivamente); altura de plantas e de espigas (AP e AE); produção de espigas e de grãos (PE e PG); coloração de grãos $(\mathrm{Cor})^{(2)}$; massa de 100 grãos (McemG); densidade real de grãos (Dens); teor de nitrogênio nas folhas(NF); e teor de proteína nos grãos (ProtG).

\begin{tabular}{|c|c|c|c|c|c|c|c|c|c|}
\hline \multirow[t]{2}{*}{ Variáveis } & \multirow[t]{2}{*}{ CV (\%) } & \multirow[t]{2}{*}{ Nível de N } & \multirow{2}{*}{$\begin{array}{c}\text { Média } \\
\text { geral }\end{array}$} & \multirow[t]{2}{*}{$\mathrm{p}^{(3)}$} & \multirow[t]{2}{*}{ Máximo } & \multirow[t]{2}{*}{ Mínimo } & \multicolumn{3}{|c|}{ Média } \\
\hline & & & & & & & Genitores & Híbridos & Testemunhas \\
\hline \multirow[t]{2}{*}{$\mathrm{C} 1$} & 4,34 & $\mathrm{~A}$ & 57,357 & 0,0933 & 61,236 & 51,307 & 54,731 & 58,007 & 57,408 \\
\hline & & $\mathrm{B}$ & 57,856 & & 61,719 & 51,348 & 56,052 & 58,446 & 56,600 \\
\hline Média & & & 57,606 & & 61,195 & 52,333 & 55,392 & 58,227 & 57,004 \\
\hline \multirow[t]{2}{*}{$\mathrm{C} 2$} & 7,63 & $\mathrm{~A}$ & 56,112 & 0,0109 & 60,633 & 47,081 & 52,024 & 57,160 & 55,880 \\
\hline & & $\mathrm{B}$ & 57,424 & & 66,095 & 51,600 & 55,712 & 58,038 & 55,746 \\
\hline Média & & & 56,768 & & 60,776 & 50,807 & 53,868 & 57,599 & 55,813 \\
\hline \multirow[t]{2}{*}{ C3 } & 5,56 & $\mathrm{~A}$ & 54,201 & 0,0017 & 59,890 & 47,143 & 51,232 & 55,008 & 53,618 \\
\hline & & $\mathrm{B}$ & 55,342 & & 59,610 & 50,867 & 53,676 & 55,871 & 54,338 \\
\hline Média & & & 54,771 & & 58,917 & 49,005 & 52,454 & 55,439 & 53,978 \\
\hline \multirow[t]{2}{*}{$\mathrm{AP}$} & 3,59 & $\mathrm{~A}$ & 190,060 & 0,3842 & 215,000 & 152,810 & 171,534 & 194,066 & 195,690 \\
\hline & & $\mathrm{B}$ & 190,756 & & 215,952 & 161,381 & 174,037 & 194,241 & 197,012 \\
\hline Média & & & 190,408 & & 215,476 & 158,762 & 172,786 & 194,153 & 196,351 \\
\hline \multirow{2}{*}{$\mathrm{AE}$} & 6,16 & A & 93,273 & 0,0387 & 115,952 & 69,095 & 82,037 & 95,144 & 101,714 \\
\hline & & $\mathrm{B}$ & 95,448 & & 132,429 & 72,810 & 84,735 & 97,398 & 102,000 \\
\hline Média & & & 93,980 & & 117,262 & 72,833 & 83,386 & 96,271 & 101,857 \\
\hline \multirow[t]{2}{*}{$\mathrm{PE}$} & 9,33 & A & $7.169,7$ & 0,0755 & $9.138,7$ & $3.206,0$ & $5.238,6$ & $7.712,5$ & $6.629,5$ \\
\hline & & $\mathrm{B}$ & $7.391,8$ & & $9.467,1$ & $4.184,1$ & $5.616,5$ & $7.865,2$ & $7.126,2$ \\
\hline Média & & & $7.281,6$ & & $9.233,1$ & $3.989,1$ & $5.427,6$ & $7.788,8$ & $6.877,8$ \\
\hline \multirow[t]{2}{*}{ PG } & 7,67 & $\mathrm{~A}$ & $5.850,1$ & 0,0965 & $7.531,1$ & $2.512,0$ & $4.251,8$ & $6.301,9$ & $5.380,7$ \\
\hline & & B & $5.978,5$ & & $7.636,8$ & $3.161,5$ & $4.447,8$ & $6.389,9$ & $5.719,2$ \\
\hline Média & & & $5.915,4$ & & $7.419,1$ & $2.836,7$ & $4.349,8$ & $6.345,9$ & $5.550,0$ \\
\hline \multirow[t]{2}{*}{ Cor } & 3,84 & $\mathrm{~A}$ & 13,027 & 0,5638 & 15,000 & 11,667 & 13,000 & 13,139 & 12,083 \\
\hline & & $\mathrm{B}$ & 13,061 & & 14,667 & 11,667 & 12,667 & 13,222 & 12,500 \\
\hline Média & & & 13,044 & & 14,667 & 11,833 & 12,833 & 13,181 & 12,292 \\
\hline \multirow[t]{2}{*}{ McemG } & 5,85 & A & 33,465 & 0,1151 & 38,345 & 28,887 & 31,637 & 34,020 & 32,589 \\
\hline & & B & 33,829 & & 37,690 & 28,379 & 31,691 & 34,457 & 32,993 \\
\hline Média & & & 33,648 & & 38,018 & 29,106 & 31,664 & 34,239 & 32,791 \\
\hline \multirow[t]{2}{*}{ Dens } & 1,74 & A & 1,2583 & 0,8501 & 1,296 & 1,232 & 1,259 & 1,257 & 1,271 \\
\hline & & $\mathrm{B}$ & 1,2579 & & 1,300 & 1,227 & 1,250 & 1,259 & 1,266 \\
\hline Média & & & 1,2580 & & 1,286 & 1,235 & 1,255 & 1,258 & 1,269 \\
\hline \multirow[t]{2}{*}{$\mathrm{NF}$} & 9,47 & A & 2,683 & 0,069 & 3,178 & 2,280 & 2,668 & 2,703 & 2,536 \\
\hline & & $\mathrm{B}$ & 2,739 & & 3,268 & 2,316 & 2,681 & 2,761 & 2,671 \\
\hline Média & & & 2,711 & & 3,026 & 2,298 & 2,675 & 2,732 & 2,603 \\
\hline \multirow[t]{2}{*}{ ProtG } & 7,81 & A & 9,769 & 0,0108 & 11,206 & 8,662 & 10,067 & 9,666 & 10,025 \\
\hline & & $\mathrm{B}$ & 10,006 & & 11,429 & 8,762 & 10,344 & 9,866 & 10,507 \\
\hline Média & & & 9,887 & & 11,268 & 9,084 & 10,206 & 9,766 & 10,266 \\
\hline
\end{tabular}

${ }^{(1)}$ As médias correspondem à avaliação da matriz de dados, com médias dos genótipos entre os dois níveis de $\mathrm{N}$, sem considerar a existência de subparcelas. ${ }^{(2)}$ Escala de cores composta por gradiente de coloração que se inicia no amarelo-claro, de valor 1, e finaliza no alaranjado intenso, com valor 15 (Roche, 1987). ${ }^{(3)}$ Valor de probabilidade para a comparação entre as médias das subparcelas pelo teste t de Student. 
de $\mathrm{N}$ utilizadas (Tabela 3). Esse resultado é mais um indicativo de que a menor dose de $\mathrm{N}$ foi suficiente para o bom desenvolvimento das plantas. $\mathrm{O}$ efeito da interação entre genótipos e adubação nitrogenada só foi detectado na produção de grãos. Para esta variável, obtiveram-se separadamente análises dialélicas, em cada condição de adubação nitrogenada, além de uma análise com a decomposição dos efeitos principais e interações com a dose de $\mathrm{N}$ utilizada.

Os resultados da análise dialélica para as variáveis avaliadas, obtidas pelo modelo de Gardner \& Eberhart (1966), estão apresentados na Tabela 4. Com exceção de PE e PG, em ambos os níveis de adubação nitrogenada, houve efeito significativo de genótipos nos demais caracteres. A variabilidade genética entre os genitores pode ser confirmada pela grande variação das estimativas de $\mathrm{v}_{\mathrm{i}}$ (efeito de genótipos) (Tabela 5). A significância dos quadrados médios desta fonte de variação confirma a existência de variabilidade genética entre os parentais e demonstra a possibilidade de seleção de populações superiores, quanto a características de interesse como o teor de proteína nos grãos. Maiores influências associadas aos efeitos genéticos aditivos foram encontradas em relação à coloração e à massa de 100 grãos, responsáveis por 85,05 e $51,14 \%$ da soma de quadrados de tratamentos, respectivamente. Em ProtG, esse índice atingiu 43,92\% e, como não houve efeito de heterose total significativo, concluiu-se que há predominância de efeitos aditivos no controle genético desse caráter. Esse fato indica a necessidade de contínuos processos de seleção para a melhoria dessa característica, o que pode ser facilitado pela ampliação da base genética das populações trabalhadas (Oliveira et al., 2004).

Em todos os caracteres, com exceção do teor de $\mathrm{N}$ nas folhas, pelo menos um dos componentes da heterose foi significativo, o que demonstra a presença, também, de efeitos não aditivos no controle genético desses caracteres. A significância da heterose média indica diferença das médias dos híbridos, em relação à média dos parentais. Conforme Vencovsky (1970), esta significância conduz à aceitação de que existe dominância no controle genético do caráter e de que a divergência das frequências gênicas entre os genitores é suficientemente grande, pelo menos em parte dos locos com dominância.

A existência de diferenças entre os genitores, quando presentes em cruzamentos entre si, pode ser verificada pelos efeitos significativos da heterose, observados nas variáveis $\mathrm{C} 1, \mathrm{C} 2$ e Dens (Tabela 4). Pode-se dizer que, nos outros caracteres, houve homogeneidade dos genitores quanto às suas participações na heterose nos híbridos. Assim, o comportamento da capacidade geral de combinação desses caracteres irá recair sobre os próprios efeitos de genótipos. Brasil (1998) comenta que efeitos de heterose de genótipos não significativos, normalmente, estão associados ao fato de se trabalhar com materiais previamente melhorados, com frequências de genes favoráveis elevadas para o caráter em avaliação.

A heterose específica é manifestada pela existência de diferenças suficientemente grandes entre as frequências gênicas, em pelo menos parte dos genitores, ou por meio de complementações específicas entre pares de genitores envolvidos em cruzamentos. De maneira

Tabela 4. Análise de variância, segundo o modelo dialélico de Gardner \& Eberhart (1966), dos caracteres: índice relativo de clorofila (SPAD), determinado aos 90, 97 e 104 dias após semeadura (C1, C2 e C3, respectivamente); altura de planta (AP); altura de espigas (AE); produção de espigas (PE); produção de grãos (PG), nos níveis A e B de adubação nitrogenada (70 e $140 \mathrm{~kg} \mathrm{ha}^{-1}$ de N, respectivamente); coloração de grãos (Cor) ${ }^{(1)}$; massa de cem grãos (McemG); densidade real de grãos (Dens); teor de nitrogênio nas folhas (NF); teor de proteína nos grãos (ProtG). Dados de nove genótipos de milho e seus cruzamentos.

\begin{tabular}{|c|c|c|c|c|c|c|c|c|c|c|c|c|c|c|}
\hline \multirow[t]{2}{*}{ Fatores de variação } & \multirow[t]{2}{*}{ GL } & \multicolumn{13}{|c|}{ Quadrado médio } \\
\hline & & $\mathrm{C} 1$ & $\mathrm{C} 2$ & $\mathrm{C} 3$ & $\mathrm{AP}$ & $\mathrm{AE}$ & Cor & McemG & Dens & $\mathrm{NF}$ & PE & PG-A & PG-B & ProtG \\
\hline Tratamentos & 44 & $4,70^{* *}$ & $5,70^{* *}$ & $5,19 * *$ & $165,60 * *$ & $98,73^{* *}$ & $0,532 * *$ & $4,423 * *$ & $0,00015 * *$ & $0,025 * *$ & $825.205 * *$ & $641.590^{* *}$ & $654.724 * *$ & $0,2047^{* *}$ \\
\hline Genótipos & 8 & $6,23 * *$ & $5,58^{*}$ & $5,80 * *$ & $286,56 * *$ & $254,22 * *$ & $2,489 * *$ & $12,439 * *$ & $0,00029 * *$ & $0,061 * *$ & $82.426^{\mathrm{ns}}$ & $159.616^{\mathrm{ns}}$ & $155.409^{\mathrm{ns}}$ & $0,4945 * *$ \\
\hline Heterose & 36 & $4,36^{* *}$ & $5,73 * *$ & $5,06^{* *}$ & $138,72 * *$ & $64,18^{* *}$ & $0,097^{\mathrm{ns}}$ & $2,641 * *$ & $0,00012^{*}$ & $0,017^{\mathrm{ns}}$ & $990.267^{* *}$ & $748.696^{* *}$ & $765.682 * *$ & $0,1402^{\mathrm{ns}}$ \\
\hline Heterose média & 1 & $65,85^{* *}$ & $110,68^{* *}$ & $94,80^{* *}$ & $3.680,74 * *$ & $1166,42 * *$ & $1,200 * *$ & $48,428 * *$ & $0,00006^{\text {ns }}$ & $0,001^{\text {ns }}$ & $29.184 .153^{* *}$ & $21.301 .016^{* *}$ & $20.265 .685^{* *}$ & $0,9275^{* *}$ \\
\hline Heterose de genótipos & 8 & $3,83 * *$ & $5,67 *$ & $2,47^{\mathrm{ns}}$ & $27,28^{\text {ns }}$ & $16,12^{\mathrm{ns}}$ & $0,118^{\mathrm{ns}}$ & $0,782^{\text {ns }}$ & $0,00016^{*}$ & $0,017^{\text {ns }}$ & $133.810^{\text {ns }}$ & $123.555^{\mathrm{ns}}$ & $230.290^{\mathrm{ns}}$ & $0,1088^{\text {ns }}$ \\
\hline Heterose específica & 27 & $2,24 *$ & $1,86^{\mathrm{ns}}$ & $2,50 *$ & $40,56^{* *}$ & $37,60 * *$ & $0,050^{\mathrm{ns}}$ & $1,496^{*}$ & $0,00010^{\text {ns }}$ & $0,017^{\mathrm{ns}}$ & $199.815^{\text {ns }}$ & $172.725^{\text {ns }}$ & $202.095^{\text {ns }}$ & $0,1204^{\mathrm{ns}}$ \\
\hline Resíduo $^{(2)}$ & 78 & 1,25 & 2,49 & 1,40 & 16,69 & 10,74 & 0,077 & 0,826 & 0,00007 & 0,013 & 151.961 & 141.579 & 136.811 & 0,0972 \\
\hline Média & - & 57,65 & 56,83 & 54,84 & 189,86 & 93,25 & 13,2 & 33,68 & 1,26 & 2,72 & 7.247 & 5.829 & 5.958 & 9,85 \\
\hline CV (\%) & - & 1,94 & 2,78 & 2,16 & 2,15 & 3,51 & 2,11 & 2,7 & 0,66 & 4,31 & 5,38 & 11,14 & 10,72 & 3,17 \\
\hline
\end{tabular}

${ }^{(1)}$ Escala de cores composta por gradiente de coloração que se inicia no amarelo-claro, de valor 1 , e finaliza no alaranjado intenso, com valor 15 (Roche, 1987). ${ }^{(2)}$ Para as variáveis PE, PG-A, PG-B e ProtG, o número de graus de liberdade do resíduo foi 77 . * e **Significativo pelo teste F, a 5 e $1 \%$ de probabilidade, respectivamente. ${ }^{\text {ns}}$ Não significativo. 
geral, a heterose específica não apresentou influência na maioria dos caracteres avaliados, com significância apenas para C1, C3, AP, AE e McemG (Tabela 4).

Em relação às variáveis $\mathrm{C} 1, \mathrm{C} 2$ e $\mathrm{C} 3$, os quadrados médios forneceram evidência de que os genitores têm comportamento heterogêneo e de que há manifestação de heterose em seus cruzamentos. Em C1, observaramse estimativas de $v_{i}$ entre $-4,11$ SPAD (genitor 9) e 4,99 SPAD (genitor 4). Este efeito genotípico se refere ao potencial de uso per se, e quanto maior for o valor dessa estimativa, melhor é o potencial do genitor para a manifestação do caráter. O maior efeito heterótico médio foi identificado em $\mathrm{C} 2$, com valor SPAD igual a 3,92, que correspondeu à superioridade média dos híbridos em relação aos parentais de 6,93\% (Tabela 5). Gardner \& Eberhart (1966) mostraram que, em cruzamentos dialélicos de variedades, a capacidade geral de combinação de uma delas $\left(g_{\mathrm{j}}\right)$ depende, também, dos efeitos expressos pela heterose de genótipos $\left(\mathrm{h}_{\mathrm{i}}\right)$. Assim, se observados como um todo, os efeitos de genótipos $\left(\mathrm{v}_{\mathrm{i}}\right)$, da heterose de genótipos $\left(h_{i}\right)$ e da capacidade geral de combinação $\left(g_{i}\right)$ mostram grande heterogeneidade entre os genitores, com destaque para os parentais DAS 2C 599 e DAS CO32, que tiveram altos valores de capacidade geral de combinação, nas duas primeiras épocas de avaliação da clorofila. Constatou-se uma possível exploração de combinações híbridas, no caráter índice relativo de clorofila, quando se consideraram avaliações aos 90 e 104 dias após plantio, em que combinações híbridas formadas a partir dos cruzamentos entre os genitores 2 e 8 (AG 7575 x P30F33) e genitores 3 e 9 (DAS 2C 599 $\mathrm{x}$ AS 1548) foram as melhores e apresentaram os índices $\mathrm{S}_{\mathrm{ij}}$ de 2,84 SPAD e 3,76 SPAD, respectivamente.

A busca por ganhos adicionais na produtividade de grãos deve ser complementada por esforços do melhoramento genético também em caracteres de interesse agronômico como a redução da altura de plantas e de espigas. Em AP e AE, verificaram-se valores de heterose média $(\overline{\mathrm{h}})$ de $22,61 \mathrm{~cm}$ e $12,73 \mathrm{~cm}$, correspondentes à superioridade de 13,16 e 15,32\%, respectivamente, dessas alturas nos híbridos, em relação aos parentais. Os genitores que obtiveram resultados mais promissores na redução tanto de $\mathrm{AP}$ quanto de AE foram: 1 (DKB 333B), 3 (DAS 2C 599) e 7 (AGN 31A31) (Tabela 5). Esses genitores tiveram

Tabela 5. Matriz das estimativas dos efeitos de genótipos $\left(\mathrm{v}_{\mathrm{i}}\right)$, heterose de genótipos $\left(\mathrm{h}_{\mathrm{i}}\right)$ e capacidade geral de combinação $\left(\mathrm{g}_{\mathrm{i}}\right)$ de nove genótipos de milho e seus cruzamentos dialélicos.

\begin{tabular}{|c|c|c|c|c|c|c|c|c|c|c|c|}
\hline \multirow[t]{2}{*}{ Estimativa } & \multicolumn{9}{|c|}{ Genitores $^{(1)}$} & \multirow[t]{2}{*}{$\mu$} & \multirow[t]{2}{*}{$\overline{\mathrm{h}}$} \\
\hline & 1 & 2 & 3 & 4 & 5 & 6 & 7 & 8 & 9 & & \\
\hline \multicolumn{10}{|c|}{ Índice SPAD determinado aos 90 dias da semeadura $(\mathrm{C} 1)$} & \multirow{4}{*}{55,23} & \multirow{4}{*}{3,024} \\
\hline $\mathrm{v}_{\mathrm{i}}$ & $-2,0396$ & 0,9438 & 3,0128 & 4,9878 & $-1,1205$ & $-0,1979$ & $-0,3419$ & $-1,1324$ & $-4,1122$ & & \\
\hline $\mathrm{h}_{\mathrm{i}}$ & 0,0051 & $-0,0587$ & $-0,3966$ & $-2,3970$ & 0,2281 & $-0,6084$ & 0,2449 & 0,7133 & 2,2693 & & \\
\hline $\mathrm{g}_{\mathrm{i}}$ & $-1,0147$ & 0,4132 & 1,1098 & 0,0969 & $-0,3322$ & $-0,7074$ & 0,0739 & 0,1471 & 0,2132 & & \\
\hline \multicolumn{10}{|c|}{ Índice SPAD determinado aos 97 dias da semeadura (C2) } & \multirow{4}{*}{53,69} & \multirow{4}{*}{3,921} \\
\hline $\mathrm{V}_{\mathrm{i}}$ & 1,0052 & $-0,8782$ & $-0,6425$ & 2,5385 & $-2,7960$ & 5,3242 & $-0,7817$ & $-2,6925$ & $-1,0770$ & & \\
\hline $\mathrm{h}_{\mathrm{i}}$ & $-1,3276$ & 0,7630 & 1,1015 & 0,2591 & 1,3135 & $-3,2429$ & 0,3907 & 1,2404 & $-0,4978$ & & \\
\hline $\mathrm{g}_{\mathrm{i}}$ & $-0,8250$ & 0,3240 & 0,7803 & 1,5284 & $-0,0845$ & $-0,5808$ & $-0,0002$ & $-0,1058$ & $-1,0362$ & & \\
\hline \multicolumn{10}{|c|}{ Índice SPAD determinado aos 104 dias da semeadura (C3) } & \multirow{4}{*}{51,94} & \multirow{4}{*}{3,629} \\
\hline $\mathrm{V}_{\mathrm{i}}$ & $-1,3847$ & $-0,0585$ & 2,0903 & 3,4868 & $-2,3680$ & $-0,5263$ & 0,8772 & $-1,6930$ & $-0,4239$ & & \\
\hline $\mathrm{h}_{\mathrm{i}}$ & 0,3950 & 0,5722 & $-2,0384$ & $-0,0771$ & 1,2033 & 0,8945 & $-0,9195$ & 0,1218 & $-0,1517$ & & \\
\hline $\mathrm{g}_{\mathrm{i}}$ & $-0,2974$ & 0,5430 & $-0,9933$ & 1,6663 & 0,0193 & 0,6314 & $-0,4809$ & $-0,7247$ & $-0,3637$ & & \\
\hline \multicolumn{10}{|c|}{ Altura de plantas $(\mathrm{cm})$} & \multirow{4}{*}{171,77} & \multirow{4}{*}{22,610} \\
\hline $\mathrm{V}_{\mathrm{i}}$ & $-9,0196$ & 9,5792 & $-9,3231$ & 6,1042 & 1,9709 & 14,6376 & $-13,4898$ & $-2,1958$ & 1,7364 & & \\
\hline $\mathrm{h}_{\mathrm{i}}$ & $-0,4331$ & $-1,7752$ & 1,1153 & $-6,5304$ & 3,0589 & 2,5671 & $-1,9157$ & 4,3275 & $-0,4145$ & & \\
\hline $\mathrm{g}_{\mathrm{i}}$ & $-4,9429$ & 3,0144 & $-3,5463$ & $-3,4783$ & 4,0444 & 9,8859 & $-8,6606$ & 3,2296 & 0,4537 & & \\
\hline \multicolumn{10}{|c|}{ Altura de espigas $(\mathrm{cm})$} & \multirow{4}{*}{83,06} & \multirow{4}{*}{12,728} \\
\hline $\mathrm{V}_{\mathrm{i}}$ & $-8,9161$ & $-9,5626$ & $-6,7233$ & 6,9160 & 5,3886 & 17,2279 & $-4,3054$ & 1,5529 & $-1,5780$ & & \\
\hline $\mathrm{h}_{\mathrm{i}}$ & $-1,4389$ & $-1,1037$ & 2,2717 & $-5,2889$ & 1,8543 & 1,9702 & 0,7980 & 2,1787 & $-1,2414$ & & \\
\hline $\mathrm{g}_{\mathrm{i}}$ & $-5,8969$ & $-5,8850$ & $-1,0899$ & $-1,8309$ & 4,5487 & 10,5842 & $-1,3547$ & 2,9551 & $-2,0304$ & & \\
\hline \multicolumn{10}{|c|}{ Massa de cem grãos (g) } & \multirow{4}{*}{31,61} & \multirow{4}{*}{2,594} \\
\hline $\mathrm{V}_{\mathrm{i}}$ & 0,4632 & 1,8636 & 0,3741 & 1,8464 & $-1,8657$ & $-1,7116$ & 1,0810 & 1,1404 & $-3,1913$ & & \\
\hline $\mathrm{h}_{\mathrm{i}}$ & 0,4409 & 0,5977 & $-0,1544$ & $-0,6579$ & $-0,0620$ & $-1,0533$ & 0,5107 & 0,2333 & 0,1450 & & \\
\hline $\mathrm{g}_{\mathrm{i}}$ & 0,6725 & 1,5295 & 0,0326 & 0,2653 & $-0,9948$ & $-1,9091$ & 1,0512 & 0,8035 & $-1,4506$ & & \\
\hline \multicolumn{10}{|c|}{ Densidade real de grãos $\left(\mathrm{g} \mathrm{mL}^{-1}\right)$} & \multirow{4}{*}{1,25} & \multirow{4}{*}{0,003} \\
\hline $\mathrm{V}_{\mathrm{i}}$ & 0,0023 & $-0,0033$ & 0,0359 & 0,0184 & $-0,0145$ & $-0,0074$ & $-0,0062$ & $-0,0172$ & $-0,0080$ & & \\
\hline $\mathrm{h}_{\mathrm{i}}$ & $-0,0025$ & 0,0109 & $-0,0136$ & $-0,0103$ & 0,0001 & 0,0031 & $-0,0008$ & 0,0059 & 0,0073 & & \\
\hline $\mathrm{g}_{\mathrm{i}}$ & $-0,0014$ & 0,0092 & 0,0044 & $-0,0011$ & $-0,0072$ & $-0,0006$ & $-0,0038$ & $-0,0027$ & 0,0033 & & \\
\hline
\end{tabular}

${ }^{(1)}$ Genótipos descritos na Tabela 1. 
estimativas favoráveis quanto à capacidade geral de combinação e contribuíram, com genes de ação aditiva, para a redução na altura das plantas e da inserção da espiga, nos cruzamentos em que participaram.

Quanto à produção de espigas (PE) e produção de grãos, com a separação das médias para cada nível de $\mathrm{N}$ na análise (PG-A e PG-B), observou-se que não houve diferença no desempenho entre as populações parentais; no entanto, quando em cruzamentos, elas produziram híbridos com comportamento diferenciado em relação às suas médias (heterose total $\mathrm{e}$ heterose média significativas) (Tabela 4). A heterose média encontrada em PE foi de $2.013 \mathrm{~kg} \mathrm{ha}^{-1}$ (Tabela 6), que correspondeu a $35,71 \%$ de superioridade da média dos híbridos, em relação aos parentais, os quais apresentaram médias de 7.650 e $5.637 \mathrm{~kg} \mathrm{ha}^{-1}$, respectivamente. Maiores contribuições para o acréscimo dessa variável podem ser oferecidas pelos genitores 6(GARRA), 7 (AGN 31A31), 9 (AS 1548) e 1 (DKB 333B).

Quando se observaram os resultados de PG, obtidos com as médias nos dois níveis de $\mathrm{N}$, e foram desdobrados os efeitos principais da interação com $\mathrm{N}$ (Tabela 7), verificou-se significância em todas as fontes de variação que envolveram interações, com exceção da heterose média $\times \mathrm{N}$. Como para os efeitos principais não houve diferença de significâncias entre as análises dialélicas realizadas em cada nível de adubação, essa detecção de efeitos significativos com interação se deu por diferenças acumulativas, decorrente das alterações de comportamento dos genitores provocadas pelo aumento do teor de $\mathrm{N}$ no solo, com consequente influência na manifestação de seus cruzamentos. A não significância da interação heterose média $\mathrm{x} \mathrm{N}$ é indicativa de que os híbridos apresentam consistência de comportamento nos dois níveis de adubação, ou seja, que a heterose média é a mesma para os dois níveis de $\mathrm{N}$, e os híbridos são superiores aos parentais.
Na dosagem de $70 \mathrm{~kg} \mathrm{ha}^{-1}$ de $\mathrm{N}$, a PG média foi de $4.454 \mathrm{~kg} \mathrm{ha}^{-1}$; na dose de $140 \mathrm{~kg} \mathrm{ha}^{-1} \mathrm{de} \mathrm{N}$, a PG média foi de $4.618 \mathrm{~kg} \mathrm{ha}^{-1}$, com heterose média de $1.720 \mathrm{e}$ $1.677 \mathrm{~kg} \mathrm{ha}^{-1}$, respectivamente (Tabela 6). A diferença entre as produções de grãos foi muito pequena e não definiu em qual situação houve maior importância dos efeitos não aditivos para a expressão do caráter PG. Esse fato está relacionado aos níveis de suplementação de $\mathrm{N}$, que não ofereceram condições de estresse para possíveis diferenças na manifestação do controle genético da PG. A deficiência de $\mathrm{N}$ tem sido relatada como de grande importância para a expressão de efeitos não aditivos e aumento da heterose quanto à produção de grãos e outros caracteres em milho (Betran et al., 2003; Medici et al., 2004). Souza et al. (2008) também identificaram importância dos efeitos aditivos em genótipos de milho, provenientes de cruzamentos entre híbridos, porém em condições mais contrastantes de adubação nitrogenada.

Em relação ao conjunto de genótipos avaliados no presente trabalho, pode-se dizer que os materiais que passaram por intensa seleção apresentaram semelhança quanto à $\mathrm{PG}$, porém com manifestação diferencial quanto à adubação nitrogenada. A seleção de genótipos parentais de maior potencial produtivo poderá ser melhor direcionada, se avaliada separadamente em diferentes condições de adubação nitrogenada, de maneira a assegurar que genótipos de alta qualidade não sejam perdidos.

$\mathrm{Na}$ coloração de grãos (Cor), observou-se significância dos efeitos de genótipo e heterose média correspondente a 0,41 pontos, que representaram $3,19 \%$ de acréscimo na coloração dos híbridos em relação aos parentais (Tabelas 4 e 6). A coloração intensa dos grãos é um aspecto de interesse para indústrias de

Tabela 6. Matriz das estimativas dos efeitos de genótipos $\left(\mathrm{v}_{\mathrm{i}}\right)$, média $(\mu)$ e heterose média $(\overline{\mathrm{h}})$ dos caracteres: produção de espigas (PE); produção de grãos (PG); coloração de grãos $(\mathrm{Cor})^{(1)}$; teor de nitrogênio nas folhas (NF); e teor de proteína nos grãos (ProtG).

\begin{tabular}{|c|c|c|c|c|c|c|c|c|c|c|c|c|}
\hline \multirow[t]{2}{*}{ Caráter } & \multirow{2}{*}{$\begin{array}{c}\text { Adubação } \\
\text { com N }\end{array}$} & \multicolumn{9}{|c|}{ Genitores $^{(2)}$} & \multirow[t]{2}{*}{$\mu$} & \multirow[t]{2}{*}{$\overline{\mathrm{h}}$} \\
\hline & & 1 & 2 & 3 & 4 & 5 & 6 & 7 & 8 & 9 & & \\
\hline PE & - & 101,28 & $-214,40$ & $-51,92$ & $-243,95$ & $-135,28$ & 238,22 & 155,49 & 1,81 & 148,75 & $5.637,17$ & $2.013,29$ \\
\hline PG & $70 \mathrm{~kg} \mathrm{ha}^{-1}$ & 54,83 & $-377,33$ & 196,97 & $-46,10$ & $-328,06$ & 269,95 & 268,92 & $-130,15$ & 90,99 & $4.453,76$ & $1.720,02$ \\
\hline PG & $140 \mathrm{~kg} \mathrm{ha}^{-1}$ & $-533,05$ & 77,00 & 92,06 & $-128,13$ & 119,00 & 55,70 & 129,72 & 300,53 & $-112,83$ & $4.616,75$ & $1.677,70$ \\
\hline PG & Média $^{(3)}$ & $-239,11$ & $-150,17$ & 144,51 & $-87,12$ & $-104,53$ & 162,83 & 199,32 & 85,19 & $-10,92$ & $4.535,26$ & $1.698,86$ \\
\hline Cor & - & $-0,8503$ & 0,4991 & $-0,1500$ & $-0,0289$ & $-0,8860$ & 0,5783 & $-0,3146$ & $-0,9476$ & 2,1000 & 12,7910 & 0,4080 \\
\hline NF & - & 0,1175 & 0,0912 & 0,0999 & 0,0620 & 0,0262 & $-0,1054$ & $-0,2299$ & 0,1628 & $-0,2243$ & 2,7190 & $-0,0120$ \\
\hline ProtG & - & 0,6716 & $-0,0042$ & $-0,1020$ & 0,0534 & 0,0441 & 0,0193 & $-0,9615$ & 0,2039 & 0,0755 & 10,1330 & $-0,3590$ \\
\hline
\end{tabular}

${ }^{(1)}$ Escala de cores composta por gradiente de coloração que se inicia no amarelo-claro, de valor 1 , e finaliza no alaranjado intenso, com valor 15 (Roche, 1987). ${ }^{(2)}$ Genitores descritos na Tabela 1. ${ }^{(3)}$ Correspondente à avaliação da matriz de dados, com médias dos genótipos entre os dois níveis de N, sem se considerar a existência de subparcelas. 
ração e agroindústrias de produtos derivados de milho. Nas estimativas dos efeitos de genótipos $\left(\mathrm{v}_{\mathrm{i}}\right)$, o genitor 9 (AS 1548) apresentou maior potencial para manifestação de coloração mais intensa (alaranjado) nos grãos. Em McemG, o comportamento da capacidade geral de combinação recaiu sobre os próprios efeitos de genótipos, em decorrência da homogeneidade dos genitores quanto às suas participações na heterose nos híbridos. Estimou-se em 2,59 g a heterose média (Tabela 5), o que representou $8,2 \%$ da média dos genitores, que foi de $31,61 \mathrm{~g}$.

Quanto à Dens, observou-se comportamento diferencial em relação a todos os outros caracteres avaliados neste trabalho. Constatou-se significância do efeito de heterose de genótipos, com o efeito de heterose média não significativo, o que demonstra mínima influência dos efeitos de dominância na manifestação desse caráter e predominância dos efeitos da capacidade geral de combinação (Tabela 4). Conforme abordado por Vencovsky \& Barriga (1992), nesta situação pode-se inferir que o caráter tem controle genético incomum, com dominância não unidirecional, ou seja, positiva em uns locos e negativa em outros. Entre os genitores de destaque, quanto à capacidade geral de combinação $\left(\mathrm{g}_{\mathrm{i}}\right)$, está o DAS 2C 599, que apresentou contribuição favorável para o aumento desse caráter, em razão de expressiva estimativa do efeito de genótipos.

Tabela 7. Análise de variância, segundo o modelo dialélico de Gardner \& Eberhart (1966), com detalhamento da metodologia de Miranda Filho \& Vencovsky (1995), e as respectivas significâncias dos quadrados médios do caráter produção de grãos, de nove genótipos de milho e seus cruzamentos.

\begin{tabular}{lrc}
\hline Fonte de variação & GL & Quadrado médio \\
\hline Tratamentos & 44 & $580.344,78^{* *}$ \\
Genótipos & 8 & $66.254,04^{\text {ns }}$ \\
Heterose & 36 & $694.587,16^{* *}$ \\
Heterose média & 1 & $20.780 .126,84^{* *}$ \\
Heterose de genótipos & 8 & $71.342,60^{\text {ns }}$ \\
Heterose específica & 27 & $135.343,34^{\text {ns }}$ \\
Resíduo a/r & 78 & $206.512,75$ \\
Tratamentos x N & 44 & $406.875,25^{* *}$ \\
Genótipos x N & 8 & $547.554,31 * *$ \\
Heterose x N & 36 & $375.613,24 * *$ \\
Heterose média x N & 1 & $19.343,77^{\text {ns }}$ \\
Heterose de genótipos x N & 8 & $633.481,81 * *$ \\
Heterose específica x N & 27 & $312.402,90 * *$ \\
Resíduo b/rl & 96 & $34.374,23$ \\
\hline Média & - & $6.045,35$ \\
CV (\%) & - & 10,49 \\
* e **Significativo pelo teste F, a 5 e $1 \%$ de probabilidade, respectivamente. \\
ns Não significativo.
\end{tabular}

Observou-se, na análise dialélica, que houve significância apenas dos efeitos de genótipos no teor de $\mathrm{N}$ das folhas (NF). Pode-se, portanto assumir que a capacidade geral de combinação (CGC) é função somente do comportamento per se dos genitores. Assim, uma possível seleção deverá ser direcionada aos parentais que apresentaram maiores estimativas positivas do efeito de genótipos, e que normalmente deverão apresentar boas médias, com destaque para o parental 8 , que teve estimativa de $\mathrm{v}_{\mathrm{i}}$ igual a

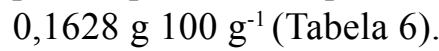

$\mathrm{O}$ teor de proteína nos grãos (ProtG) apresentou média geral de 9,89 g $100 \mathrm{~g}^{-1}$ e, diferentemente dos outros caracteres avaliados (exceto NF), a média dos

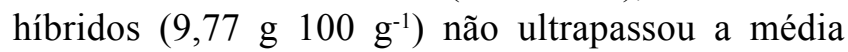

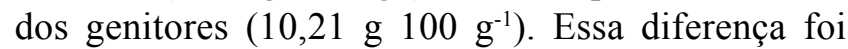
suficiente para manifestar efeito heterótico médio negativo e significativo igual a $-0,36 \mathrm{~g}^{100 \mathrm{~g}^{-1}}$ (Tabela 6). Esse comportamento tem uma importante implicação: utilizar a formação de híbridos como única estratégia não é alternativa satisfatória em programas de melhoramento para o aumento do teor de proteína nos grãos de milho. Medici et al. (2004) também encontraram resultados que indicaram existência de heterose negativa no teor de $\mathrm{N}$ nos grãos, ao trabalhar com linhagens de milho contrastantes no uso de $\mathrm{N}$, em cruzamentos dialélicos. No presente trabalho, o efeito de heterose total não apresentou significância, e a estimativa da heterose média foi muito pequena. Pode-se dizer, portanto, que efeitos de dominância têm pouca importância na manifestação desse caráter. Assim, deve-se buscar o aproveitamento de genes de efeito aditivo, de maior importância para expressão desse caráter, por meio da seleção recorrente para obtenção de parentais com maiores teores de proteína. Os materiais que mais se destacaram no aumento de ProtG foram os genitores DKB 333B e P 30F33, com estimativas $\mathrm{v}_{\mathrm{i}}$ iguais a $0,67 \mathrm{~g}$ e $0,20 \mathrm{~g} 100 \mathrm{~g}^{-1}$, respectivamente.

\section{Conclusões}

1. A produção de grãos de milho apresenta controle genético variável, de acordo com a disponibilidade de nitrogênio.

2. Existe variabilidade genética entre as populações parentais quanto ao teor de proteína nos grãos, o que possibilita a seleção de populações superiores por meio de seleção recorrente. 
3. A capacidade geral de combinação dos parentais possui efeito importante na manifestação do caráter teor de proteína nos grãos.

4. As populações DKB 333B, P 30F33 e AS 1548 apresentam bom potencial como parentais, quanto ao aumento das frequências alélicas favoráveis ao aumento no teor de proteína nos grãos.

\section{Agradecimentos}

À Escola de Agronomia e Engenharia de Alimentos, da Universidade Federal de Goiânia, pela oportunidade e apoio na condução dos experimentos; ao Conselho Nacional de Desenvolvimento Científico e Tecnológico, por concessão de bolsa.

\section{Referências}

BETRAN, F.J.; BECK, D.; BÄNZIGER, M.; EDMEADES, G.O. Genetic analysis of inbred and hybrid grain yield under stress and nonstress environments in tropical maize. Crop Science, v.43, p.807-817, 2003.

BRASIL, E.M. Variabilidade genética, heterose e efeitos de endogamia em populações de milho em cultivo normal e "safrinha". 1998. 212p. Tese (Doutorado) - Universidade Federal de Goiás, Goiânia.

DEUTSCH, M.J. (Ed.). Official methods of analysis of AOAC International. Arlington: AOAC International, 1995. 65p.

FERREIRA, A.C. de B.; ARAÚJO, G.A. de A.; PEREIRA, P.R.G.; CARDOSO, A.A. Características agronômicas e nutricionais do milho adubado com nitrogênio, molibdênio e zinco. Scientia Agricola, v.58, p.131-138, 2001.

GALVÃO, J.C.C.; MIRANDA, G.V. Tecnologias de produção de milho. Viçosa: UFV, 2004. 336p.

GARDNER, C.O.; EBERHART, S.A. Analysis and interpretation of variety cross diallel and related populations. Biometrics, v.22, p.439-452, 1966.

JESUS, W.C. de; BRASIL, E.M.; OLIVEIRA, J.P. de; PINTO, G.R.C.; CHAVES, L.J.; RAMOS, M.R. Heterose para teor de proteína no grão em cruzamentos entre populações de milho derivadas de híbridos comerciais. Pesquisa Agropecuária Tropical, v.38, p.32-38, 2008.

LEA, P.J.;AZEVEDO, R.A. Nitrogen use efficiency. 1. Uptake of nitrogen from the soil. Annals of Applied Biology, v.149, p.243-247, 2006.

LIMA, G.J.M.M. de; BELLAVER, C. Grãos de valor agregado na produção de rações para aves. In: SIMPÓSIO INTERNACIONAL ACAV-EMBRAPA SOBRE NUTRIÇÃO DE AVES, 1., 1999, Concórdia. Anais. Concórdia: Embrapa-CNPSA, 1999. p.36-46.

MEDICI, L.O.; PEREIRA, M.B.; LEA, P.J.; AZEVEDO, R.A. Diallel analysis of maize lines with contrasting responses to applied nitrogen. Journal of Agricultural Science, v.142, p.535-541, 2004.
MEDICI, L.O.; PEREIRA, M.B.; LEA, P.J.; AZEVEDO, R.A. Identification of maize lines with contrasting responses to applied nitrogen. Journal of Plant Nutrition, v.28, p.903-915, 2005.

MIRANDA FILHO, J.B.; VENCOVSKY, R. Analysis of variance with interaction of effects. Revista Brasileira de Genética, v.18, p.129-134, 1995.

OLIVEIRA, J.P. de; CHAVES, L.J.; DUARTE, J.B.; BRASIL, E.M.; FERREIRA JÚNIOR, L.T.; RIBEIRO, K. de O. Teor de proteína no grão em populações de milho de alta qualidade protéica e seus cruzamentos. Pesquisa Agropecuária Tropical, v.34, p.45-51, 2004.

OLIVEIRA, J.P. de; CHAVES, L.J.; DUARTE, J.B.; BRASIL, E.M.; RIBEIRO, K. de O. Qualidade física do grão em populações de milho de alta qualidade protéica e seus cruzamentos. Pesquisa Agropecuária Tropical, v.37, p.233-241, 2007.

PAES, M.C.D. Aspectos físicos, químicos e tecnológicos do grão de milho. Sete Lagoas: Embrapa Milho e Sorgo, 2006. 6p. (Embrapa Milho e Sorgo. Circular Técnica, 75).

ROCHE. The Roche yolk colour fan: directions for use. Basel: F. Hoffman La Roche, 1987.

RODRIGUES, M.C.; CHAVES, L.J. Heterosis and its components in crosses among high quality protein maize populations. Crop Breeding And Applied Biotechnology, v.2, p.281-290, 2002.

RODRIGUES, M.C.; CHAVES, L.J.; PACHECO, C.A.P. Heterosis in crosses among white grain maize populations with high quality protein. Pesquisa Agropecuária Brasileira, v.41, p.59-66, 2006.

SANTOS, H.G. dos; JACOMINE, P.K.T.; ANJOS, L.H.C. dos; OLIVEIRA, V.A. de; OLIVEIRA, J.B. de; COELHO, M.R.; LUMBRERAS, J.F.; CUNHA, T.J.F. (Ed.). Sistema brasileiro de classificação de solos. 2.ed. Rio de Janeiro: Embrapa Solos, 2006. $306 \mathrm{p}$.

SAS Institute. SAS/STAT software: changes and enhancements through release 8.2. Cary: SAS Institute, 2002.

SOUZA, L.V. de; MIRANDA, G.V.; GALVÃO, J.C.C.; ECKERT, F.R.; MANTOVANI, É.E.; LIMA, R.O.; GUIMARÃES, L.J.M. Genetic control of grain yield and nitrogen use efficiency in tropical maize. Pesquisa Agropecuária Brasileira, v.43, p.1517-1523, 2008.

VENCOVSKY, R. Alguns aspectos teóricos e aplicados relativos a cruzamentos dialélicos de variedades. 1970. 59p. Tese (Livre Docência) - Escola Superior de Agricultura Luiz de Queiroz, Piracicaba.

VENCOVSKY, R.; BARRIGA, P. Genética biométrica no fitomelhoramento. Ribeirão Preto: Sociedade Brasileira de Genética, 1992. 496p.

VILLEGAS, E.; ORTEGA, E.; BAUER, R. Métodos químicos usados en el CIMMYT para determinar la calidad de proteína de los cereales. Ciudad de México: Centro Internacional de Mejoramiento de Mayz y Trigo, 1985. 34p.

Recebido em 15 de janeiro de 2009 e aprovado em 29 de maio de 2009 